\title{
LA LENGUA DE LOS MANUSCRITOS ALJAMIADO-MORISCOS COMO TESTIMONIO DE LA DOBLE MARGINACIÓN DE UNA MINORÍA ISLÁMICA
}

\begin{abstract}
Al observar por primera vez un manuscrito aljamiado, y resueltas las dificultades que entraña su lectura en caracteres árabes en los que estaba transliterado, tuve la impresión de no haber acertado en la elección del mismo, ya que el contenido misceláneo que presentaba el estado fragmentario de alguno de sus capítulos y la aparente dispersión temática que ofrecía, así como la extraña "amalgama" árabe y castellana en la que estaba redactado, no me proporcionaba el corpus idóneo para mi pretendida investigación.

Un nuevo intento de selección, orientado por los diferentes catálogos que de la literatura aljamiada existen ${ }^{1}$, me hizo reconsiderar mis presupuestos y no tratar de buscar una unidad temática, establecida apriorísticamente, a base de uno o varios manuscritos, sino considerar cada uno en sí mismo y estudiarlo tal y como se nos presenta. Así quedaba puesto de relieve lo que constituía el objetivo primordial de esta literatura, las vivencias que de modo reiterativo preocupaban y ocupaban a los moriscos en su quehacer literario, cuyos devotos debieron custodiar como último manantial subterráneo del que fluía la práctica y conocimiento del Islam, en aquel escenario histórico en el que se desarrollaba la vida de la comunidad ${ }^{2}$.

${ }^{1}$ Fundamentalmente, E. SAAvedra, Discursos leidos ante la Real Academia Española, Madrid, 1978 (en adelante, SAAVEDRA, Discursos); J. RIVERA y M. ASİN, Manuscritos árabes y aljamiados en la Biblioteca de La Junta, Madrid, 1912; E. OCHOA, Catálogo razonado de los manuscritos españoles existentes en la Biblioteca Real de París, 1884.

${ }^{2} \mathrm{El}$ têrmino comunidad no hace referencia a aspectos lingüísticos entre los moriscos que presupongan una consideración unitaria, sino a elementos culturales y religiosos comunes que los vinculan.
\end{abstract}


Un hecho de fácil constatación es el espíritu religioso del que están impregnados, la orientación hacia la práctica de sus consideraciones teóricas, el carácter abreviado y compendiado de los rituales que en ellos se describen, como cabe esperar para el angosto espacio que permitía la vida espiritual. Ya que la preocupación religiosa es lo que se manifiesta de manera más relevante en los textos aljamiados, en los que constituye la verdadera columna vertebral que inserta no sólo la creencia y la práctica de la religión sino la actitud vital que de ella emana ${ }^{3}$, me he propuesto aquí el análisis de algunas cuestiones lingüísticas que presentan estos textos, enfocándolas desde la doble perspectiva que conforma el ideal lingüístico del árabe, como expresión adecuada del pensamiento religioso musulmán y la realidad del castellano, teñido de mayor o menor matiz dialectal, en el que diariamente se comunicaban los moriscos de Castilla y Aragón, como resultado de varios siglos de convivencia entre aquéllos que sólo, quizá, las creencias hicieron diferenciar.

Fruto de estos presupuestos, los escritos en aljamía ofrecen una lengua en la que el árabe y el romance se combinan de modo singular, cuyas principales características, que afectan a las estructuras fónicas morfosintácticas y semánticas ya han sido determinadas por otros investigadores que se han ocupado de su estudió. No obstante, quiero hacer aquí algunas observaciones que por ser comunes a los manuscritos por mí estudiados, pueden tal vez permitir una valoración complementaria de la lengua que presentan los textos en aljamía.

A pesar de que el castellano es la lengua en la que fueron redactados y traducidos, la plena comprensión de los escritos en aljamía no es posible sin explicar, a un tiempo, la fuerte impronta árabe que reciben, y a pesar de esta marcada influencia árabe, no se observa un resultado homogéneo que, de alguna manera,

\footnotetext{
${ }^{3}$ Ello es especialmente visible en el Islam: "El carácter religioso, que separaba a los moriscos del resto de los españoles, predomina en sus producciones, como hijas legítimas de las arábigas" (SAAvEDRA, op. cit., p. 11). Parecida observación hace J. PENELla: "La mayor parte de los ejemplares manuscritos 'aljamiados', árabes y españoles, son del siglo XVI y nos describen un cuadro de cultura religiosa de los moriscos viviendo en la médula de la sociedad cristiana" ("El sentimiento religioso de los moriscos españoles emigrados: nota para una literatura morisca en Túnez" Actas del Coloquio internacional sobre literatura aljamiada y morisca, Madrid, 1978, p. 449; en adelante, Actas).

${ }^{4}$ No doy aquí más bibliografía que la utilizada para la elaboración de este estudio, consciente de que en las obras que en él se citan podrá hallar el lector una amplia información sobre el tema.
} 
puede dejar translucir el posible grado de arabización lingüistica de la comunidad, exceptuando quizá algunos elementos léxicos. En este sentido sería esclarecedor el estudio de las frecuencias con que se producen determinados hechos, que no hemos realizado.

Del propio estilo de esta literatura y de la traducción al castellano de los pasajes árabes intercalados, así como de determinados arabismos léxicos que precisan también traducción o explicación, parece deducirse que a aquellos a quienes iba dirigida habían llegado al olvido casi general del árabe; hecho del que frecuentemente se lamentan y reprochan, en ocasiones, como causa de algunas de sus desventuras, y que originó, a su vez, una cierta segregación de los moriscos en las localidades en las que se establecieron después de la expulsión.

Cabe, pues, preguntarse a qué responde entonces la utilización del árabe en los escritos en aljamía si, como es sabido, estos textos eran de divulgación exclusivamente interna entre los miembros de la comunidad, y, por lo que se deduce, dicho empleo dificultaba la comprensión de los mismos. Creemos que el uso del árabe en los textos aljamiados, como puede observarse en los que han sido catalogados, es selectivo, está motivado por el contenido que expresa, e íntimamente vinculado a él. Parece que la reproducción del Corán, casi siempre fragmentaria, lo fundamental de la liturgia y ciertas oraciones de especial valor se nos presentan como el límite máximo de arabización en el que formalmente no cabía la mera traducción, no por razones lingüisticas sino poŕ los valores espirituales que al árabe se asociaban.

La dificultad que representaba la intercalación del texto árabe se solventaba, generalmente, por una tradición interlineal que evitaba la difícil situación teológica que planteaba la traducción del Corán, como ha señalado J. Vernet ${ }^{5}$. Otras veces en lugar de traducir se sintetiza, de manera brevísima, la finalidad para la que se aplicaba la recitación de tal o cual oración en árabe. En los manuscritos aljamiados son frecuentes las indicaciones de este tipo: para la kabeça dirás: (oración en árabe); I ku ando terrnâs engustiy $a$ dirás: (oración en árabe), $i-k u^{w}$ ando irás al almakabir o pasarás por él dirás (oración en árabe), etc.

También en árabe, aparecen determinados clichés narrativos que se dan constantemente en los textos aljamiados y que, en ocasiones, se calcan en castellano, pero que normalmente no se traducen, lo que nos hace pensar que pudieran tener alguna vigencia

${ }^{5} \mathrm{~J}$. VERNET, "La exégesis musulmana tradicional en los coranes aljamiados" Actas. 
en la lengua oral. Comenzando por la basmala, que encabeza la mayoría de los relatos aljamiados, se emplean también toda una serie de invocaciones, fórmulas doxológicas que acompañan la mención de personajes reverenciados por su piedad, fórmulas de salutación, etc., que se insertan en el discurso castellano y le dan un matiz especial. Como ilustración reproduzco varios fragmentos en los que figuran algunos de los más frecuentes:

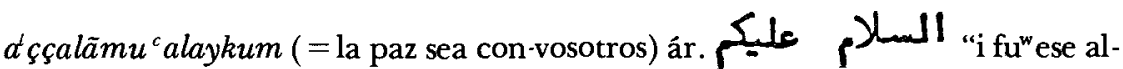
annabi(ṣ̂'am), i díxole: -A 'ccalămu ' alaykum, jyă raçūlu Al.lah!’’6.

"i dent"ró 'Umar a kasa de Abu Šahma i t’ rovólo ad Abũ Šahma ke yantaba, i díšole: - $A^{1}$ cçalāmu ' alayka, yả fijo. Disó Abu Šahma:Wa' alayka, ;yā padre!"?

'alayhii'ç̧alām(=la paz sea sobreél)är.

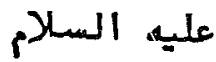

"Ent-ad-akellok 'lamól-annabi, 'alyhi i'ççalam, ada 'Ali ibnu Abí Tâalib, i díxole" ( $L B$, p. 106).

"laora đeçendiy 6 Jibril, 'alayhi i'ççalãm, i dišo. . ." (B.N.P., 774).

${ }^{c} a z z a$ wa jal.la (=engrandecido y glorificado sea), ár.

"i darás la karrta ad-al-Muhalhal, i venirme as kon la rrespuwesta, si kerrá Al.lah, 'azza wa jal.la..." ( $L B$, p. 220).

Al.lahu, 'azza wa jal.la, ke no ay otro señor sino él" (B.N.P., 774).

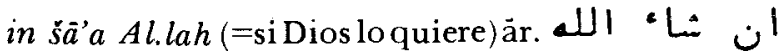

$\mathrm{pu}^{\mathrm{w}}$ es aperçebidvos para sallir dî̃a de alḥamiç, in šā'a Al.lah (LB, p. 131).

raçülu Al.lahi (=mensajero de Dios), ár. رمول

Dixo Muhammad, raçūlu Al.lahi, ¿̇i por ké es akello? ( $L B$, p. 106).

dišole c Ayša, -lyā raçulu Al.lah!, manda a otro ke lo faga (B.N.P., 774).

radiyaAl.hahu'anhu(=esté satisfecho Dios deél),ár. رضي الله عنه

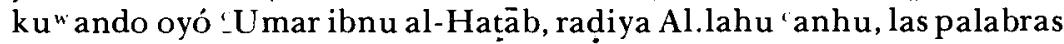
del a'nnabi" (LB, p. 104).

i ffu' ese Bilãl llorando fasta ke llegó a kasa de Fățima, raḍiya Al.lahu canha, i dišo" (B.N.P., 774).

rahimahu Al.lahu (tenga piedad Dios de él) ár. للإ اله

I ya al-Ā șyad guerreó verdadero alj̄ihāa ( = guerra santa) d-akîy-a ke murìyó, rahimahu Al.lahu (LB. p. 121).

șal. lā Al. lahu calayhi wa çal. lam (= bendígale Dios y déle salvación) ár.

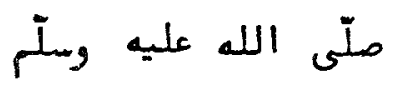

"El "Libro de las batallas", ed. A. Galmés de Fuentes, Madrid, 1978, p. 192; en adelante, $L B$.

${ }^{7}$ B.N.P., 774; en adelante nos referiremos así al manuscrito 774 de la B.N.P., cuya edición y estudio aparecerá próximamente en Actas. 
la ora ke tornó el mensajero de Al.lah, șal.la Al.lahu calayhi wa çai.lam, de la batalla de al-Muștalaq ( $L B$, p. 103).

$\mathrm{pu}^{\mathrm{w}}$ es qu' ando ell annabī, șal.la Al.lahu ${ }^{\mathrm{c}}$ alayhi wa çal.lam, mandó ke lo fizì ese Abũ Bakri, dîšole 'ayša... (B.N.P., 774).

tá ālā (= ensalzado sea) ár. ज

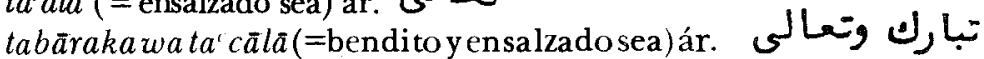

I ya Al.lah, tacālã, envìó a kada uno al-annabī a las jentes" ( $L B$, p. 131).

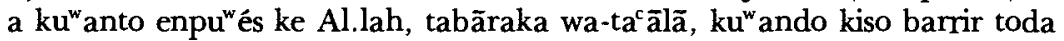
rrudeza de las tì erras ( $L B$, p. 122$)$.

waalhamduli-l.lahirabbill'alamina (=y la alabanza sea para Dios, señor del universo) ár.

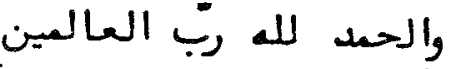

I depu" és 'Amir guerreó en defensì ón de $a^{1}$ ddin (= religión) del aliçlam d-akî́-a ke lo alkançó la müerte. Wa alḩamdu lil.la-lahi rabbī il-cālamina $(L B$, p. 145$)$.

Esto es lo ke nos a pelegado por 'Alí Bnu Jãair alfáraçiyyo, wa alhamdu li-l.lahi rabbi al ' alamina (B.N.P., 774).

En árabe son expresados los vocablos coránicos, nombres propios de ángeles, de profetas, de libros sagrados, etc., así como nombres que se refieren al cómputo del tiempo, regido por el calendario lunar con el que se establecían las festividades religiosas ${ }^{8}$ o los momentos del día en que debía realizarse la oración. En este sentido son ilustrativas las indicaciones que aparecen en algún manuscrito con anotaciones de tipo personal y que ponen de relieve el sentimiento del morisco, consciente de estar presidido por un cómputo en el que no se integraba de modo natural: ". . .tuvimos Pascua de Ramadán al çaguero de oitober, y despuós naçió Alí de Pansa a diez y ocho de noviembre, año de mil y quinientos y ochenta y cuatro, al candario de los cristianos erejes". "Nació mi hijo Içe de Zeyme a quinze de dezembre de mil y quinientos y ochenta al candario de los cristianos". ". . . mi fijo Mohamad de Zeyne a doze de setiembre, año de mil quinientos sesenta y cuatro al candario de los cristianos erejes. . ."etc. ${ }^{9}$ "Memoria seya de cuando me casé iyó Mohamad de Zeam con Axa de Amad y fué a quinze dias del mes de agosto del año mil y quinientos y noventa y cinco a cuenta de los descreyentes" 10 .

La necesidad de conocer el calendario lunar con la finalidad de acomodar a él la práctica de la fe se pone de manifiesto en muchos pasajes que la literatura aljamiada dedica a este propósi-

${ }^{8}$ F. DE LA GRANJA, "Fiestas cristianas en Al-Andalus", 'AlAn, 35 (1970), 119-142.

${ }^{9}$ B.N.M. Gg. $41, \bmod .5228$.

${ }^{10}$ B.N.M. Gg. 81, mod. 5267 , 
to; abundan escritos como el que sigue: "los meses del año al conto arabí"ll; "capítulo que fabla de las oras que son eslitas para nombar ad Al.lah", etc. ${ }^{12}$

Es observable el hecho de que en este nivel de utilización del árabe no se producen interferencias con el castellano, sino que se mantiene perfectamente delimitado y, aunque son frecuentes las incorrecciones de tipo ortográfico y las alteraciones fonéticas, no obedecen a fenómenos de adaptación al romance y sí, en cambio, son frecuentes los ejemplos de dialectalización del árabe o los que reflejan influencias de otras lenguas en éste, como los casos que señala Buzineb: "Las características fonéticas árabes que asoman en nuestros manuscritos a veces marcan la etapa intermedia de la evolución desde el árabe clásico al árabe vulgar de Marruecos como en el caso de la vocal de disyunción en la posición $c v c c>$. cucvc. Otras veces los resultados registrados en nuestros documentos son los aún vigentes en este país como la pérdida del alargamiento del árabe clásico, la menor fuerza de la 'imãla, el paso de a > o, la confusión de la pareja d-z, su desen. fatización, en $d, d$, su ensordecimiento en $t$ - $t$, paso de $h a h$, de ${ }^{c} a$ $\dot{g}$, déa h, pérdida de la-h final del femenino, desenfatización de la sad. . . etc."'13 Y que muestran la estrecha relación entre estos textos y los principales núcleos que acogieron a los moriscos como Rabat, Salé, Tetuán y suponen en filiaciones semejantes para Argel y Túnez.

En las circunstancias que hemos señalado hasta aquí, nos parece poder deducir que la gran mayoría de los moriscos tendría un conocimiento meramente pasivo de estos pasajes árabes, que, por otra parte, constituirían elementos angulares en la práctica de la fe.

En cuanto al empleo de los caracteres árabes, cuyo uso fue muy frecuente en sus escritos, es lógico pensar que no entrañaría tales dificultades de comprensión, pues una vez conocido el sistema de transliteración del castellano, les permitiría no sólo leer los textos en aljamía, sino también, aunque mecánicamente, los pasajes y oraciones árabes, que aun sin entenderse adquirirían pleno va$\operatorname{lor}^{14}$.

${ }^{11}$ B.N.M. Gg. XXVIII.

${ }^{12}$ B.N.M. Gg. 81, mod. 5267

${ }^{13} \mathrm{H}$. BUZINEB, Interferencias lingüisticas del árabe en el español (tesis doctoral inédita, Madrid, 1979, p. 321, t. 2).

${ }^{14} \mathrm{~L}$. CARDAILlaC, Morisques et chrétiens. Une affrontement polémique (1492-1620), Paris, 1977, pp. 56 ss, véase ahora trad. esp. Madrid-México, 1979. 
El interés de estar en posesión de estas oraciones se revela con frecuencia en nuestros manuscritos. Veamos lo que se aconseja en el ms. 774, B.N.P., para una de ellas:

E konvi' ene sobre todo muçlim ke deprenda esta rrogarya. E, amost $t^{\mathrm{a}}$ radla $a^{w} v^{w}{ }^{w} t^{a}{ }^{\mathrm{a}}$ ras mujeres e hijos, e kiyen no alkançara a saberla leer o saberla de korçón, esk'ríbala en un papel o pargamino e póngasela debasó de su kabeça en su füesa kuwando morra, ke Al.lah no le menosp ${ }^{\mathrm{e}}$ reçi ${ }^{y}$ a su walardón i a provecharl-á kon akello.

Por otra parte, son frecuentes en los manuscritos en aljamía los ejercicios caligráficos y las lecciones indispensables para dotar a los lectores de conocimientos elementales para la lectura de textos transliterados en caracteres árabes.

Parece, pues, que el empleo de los signos árabes constituiría de por sí un instrumento eficaz para la práctica de la religión, accesible a la mayoría de los miembros de la comunidad, quienes instruían a sus hijos, llegados a una edad que les permitía asumir el riesgo de su práctica en la clandestinidad. Ello unido, como ha señalado $\mathrm{O}$. Hegyi ${ }^{15}$, a una açtitud general entre los musulmanes de atribuir a sus letras valores mágicos y simbólicos, íntimamente vinculados a la religión y que responderían más que al deseo de hacer ininteligibles sus escritos a los cristianos - que ignoraban normalmente su existencia - a un deseo explícito de manifestación externa de pertenencia a la ummma musulmana.

La influencia de los modelos árabes se manifiesta además en la distorsión de la sintaxis castellana, que corresponde, en general, a la propia de la lengua sencilla y coloquial, a la que se acomodan una serie de estructuras de la sintaxis externa e interna del árabe que le prestan un carácter especial. Los principales elementos sintácticos y estilísticos de origen árabe en los textos aljamiados y, en general, de los textos de traducción han sido determinados por A. Galmés de Fuentes ${ }^{16}$ y los numerosos calcos semánticos por R. Kontzi ${ }^{17}$ y que, por tanto, no vamos a tratar.

${ }^{15} \mathrm{O}$. HEGYI, "El uso del alfabeto árabe por minorías musulmanas y otros aspectos de la literatura aljamiada, resultantes de circunstancias históricas y sociales análogas", Acîas, pp. 147-163.

${ }^{16}$ A. GALMÉS DE FUENTES, Influencias sintáḉicas y estilísticas del árabe en la prosa medieval castellana, Madrid, 1956; "Interés en el orden lingüísticode la literatura española aljamiado-morisca", CLR(IO), 527-546; Historia de los de los amores de París y Viana, Madrid, 1970; El "Libro de las batallas", Madrid, 1975.

${ }^{17} \mathrm{R}$. KonTZI, "Aspectos del estudio de textos aljamiados", BICC, 25 (1970), 196-213. 
En cuanto al arabismo léxico, tan abundante, hemos constatado un hecho que queremos subrayar. Hay un número relativamente bajo de ciertos arabismos, de poca frecuencia, cuyo carácter culto, o restringido a ciertos aspectos jurídicos o doctrinales, hace necesaria la traducción, lo que induce a pensar que no son términos de la lengua común. Hay, por otro lado, gran número de voces de aparición frecuente, comunes a todos los textos, inclusive los menos arabizantes: su fonética está adaptada al romance ${ }^{18}$, y están integrados gramaticalmente en él; intervienen, además, en la traducción al romance de los pasajes árabes intercalados. De la reunión de estos datos, creo que podemos deducir que son términos pertenecientes a la lengua común - cotidianade los moriscos. Aunque etimológicamente sean de origen árabe, estos vocablos fueron absorbidos por el castellano y semánticamente estructurados dentro de una esfera conceptual particular, en la que establecen nuevas relaciones, distintas ya, de las que poseían en su origen ${ }^{19}$, y que constituirían lo que habría de ser un léxico elemental del mumin o creyente musulmán, susceptible de inventariar.

A continuación cito algunos ejemplos tomados de pasajes aljamiados que son traducción de otros, idénticos, escritos en árabe:

Pu"es si no por ti, !yā Muḩammad!, no ab'ín' a halaqādo Al.lah al

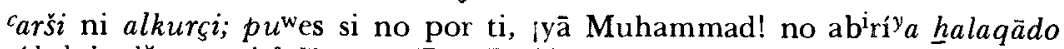
Al. lah aljanna ni fuw go... (B.N.P., 774).

Señor guwarda mi miyenboro del azzine i alimpya mi viyentere de lo haram...(B.N.P., 774).

Señor, rreģibe mis alhaçanas i da trespas de mis pekados i pon a mi mi alwadu reçebido, i mis pekados perdonados, i mi ta rabajo aga radecido $\mathrm{i}$ mis asalaes kumpiliodos" (B.N.P., 774)

Señor, no me des a oir los rruidos del fuwego ni los jiflos de jahannam $\mathrm{i}$ dame a oir los perguwenos dell aljanna.

Señor, afirma mis pi ' edes sob"re el pu"en del-assirät di'yake s-es lengarán los piyedes (B.N.P., 774).

He acumulado ejemplos, tomados de la traducción de algunas oraciones, con el fin de mostrar cómo un grupo de arabismos léxicos de estos textos funciona igual que si de palabras romances se tratara.

${ }^{18}$ A. STEIGER, Contribución a la fonética del hispano-árabe y de los arabismos del ibero-románico y el siciliano, Madrid, 1932; M. GROSMANN, "La adaptación de los fonemas árabes al sistema fonológico del romance", $R R L$, 14 (1969), 51-64.

${ }^{19} \mathrm{M}$. LÖRINCZI, "Consideraciones semánticas acerca de las palabras españolas de origen árabe", $R R L, 1$ (1969), 66-67. 
Hemos de pensar que la práctica de la religión musulmana entre los moriscos españoles proporcionaría toda una serie de términos específicos que, o bien por no poseer un término equivalente en español, o porque de haberlo se opondría al concepto por ellos evocado (por pertenecer al campo de lo específicamente islámico), dotaría a los moriscos españoles, sobre todo en sus relaciones intracomunitarias de un habla casi jergal, pero que prudentemente reprimirían en la relación con otros miembros no pertenecientes a la comunidad, pues constituiría la prueba más clara de práctica del Islam.

Hemos señalado hasta ahora una serie de características que afectan al arabismo de los textos aljamiados y cuyas causas intentamos explicar. De la misma manera que no es fácil determinar el grado de arabización adquirido por los moriscos en su habla coloquial, tampoco es muy clara la determinación del castellano que utilizaban, y si éste había adquirido un matiz especial. Dos hechos se presentan con cierta relevancia: el arcaísmo lingüístico y el matiz dialectal. Ahora bien, si tenemos en cuenta que uno y otro no son sistemáticos, y que en un mismo texto coexisten junto a una forma arcaizante otra más actual, y que junto a la solución dialectal se presenta la castellana, de tal modo que, aunque los aragonesismos sean muy frecuentes - como es lógico, dado que el núcleo fundamental de esta literatura fue redactado en Aragón - no constituyen una muestra clara del habla de ninguna región. Si tenemos en cuenta la elaboración de estos escritos, muchos de ellos copia de otros anteriores, y el destino de los mismos, adoctrinamiento y aglutinación en torno a una misma fe de los miembros de una comunidad dispersa, es probable pensar que su redacción refleje de algún modo el efecto de este afán integrador y que varias normas se den simultáneamente como si se tratara de una koiné.

Sin embargo, y pese al arcaísmo anteriormente señalado, en parte consecuencia de la fidelidad con la que los manuscritos son reproducidos y, quizá, del relativo aislamiento de la comunidad, en los textos aljamiados se observan rasgos innovadores, que afectan a la fonética y que en estas circunstancias adquieren especial interés, pues vienen a representar una ruptura con el sistema establecido para la transliteración. El yeísmo que presenta algún manuscrito ${ }^{20}$, el çeçeo que aparece en otros ${ }^{21}$, la articula-

${ }^{20}$ A. GALMÉS DE FUENTES, "Lie-yeísmo y otras cuestiones lingüísticas en un relato morisco del siglo XVII", EMP, 2, 273-307.

${ }^{21}$ D. CARDAILlaC, "Algunos problemas lingüísticos evocados a partir de 
ción interdental, fricativa, sorda de la ${\mathrm{c}-\mathrm{z}^{22}}^{22}$ o la escrupulosa distinción de la realización fricativa $u$ oclusiva de la $d$ española ${ }^{23}$, que coincide casi con exactitud con la actual, son rasgos del habla viva de los moriscos, que pese al carácter convencional de la lengua de estos escritos han podido penetrar.

Creemos, pues, que la cuestión fundamental, para la consideración de la lengua de los textos aljamiados, que subyace en lo que se está planteando aquí, es la de determinar si tales escritos pueden ser tomados como testimonio de la realidad lingüística de los moriscos, lo que nos parece muy improbable, porque contrastan además con otras producciones castellanas de los mismos ${ }^{24}$, y en consecuencia descartamos. De no ser así, en qué medida, o qué proporción puede ser establecida en la relación existente entre la lengua que presentan estos escritos y la que los moriscos utilizaban en sus relaciones cotidianas, entre ellos mismos y entre la mayoría cristiana con la que coexistían, pues no parece que sea exclusivamente un producto "alquímico" obtenido por ciertos traductores y alfaquíes, y distribuido entre los miembros de la comunidad de creyentes.

En cierto modo, la lengua de los manuscritos aljamiados presenta algunos elementos comunes que la aproximan a la categoría de lenguas especiales, aunque no me parece adecuada la etiqueta de pseudosaber con la que se ha clasificado ${ }^{25}$. Aunque es una lengua unilateral, utilizada sólo internamente en la comunidad, no nace de la necesidad sentida por los individuos, de reproducir una lengua de prestigio superior, como sería el castellano, cuyo cultivo literario practicaron también ${ }^{26}$, ya que pensamos que era ésta la lengua que hablaban, y albergamos muchas dudas de que la que aparece en sus escritos aljamiados la hubieran hablado nunca - al menos así como la conocemos. La reproducción unilateral del árabe no la intentaron, conscientes de su desconocimiento, como constataron con frecuencia, aunque respetaron su empleo para las funciones que hemos expuesto aquí.

En cuanto a la afinidad con las hablas jergales, aunque pueda

los mss. aljamiados 4944 de la Biblioteca Nacional de Madrid y V7 de la Real Academia de la Historia", Actas, pp. 413.422.

${ }^{22}$ M. SÁNCHEZ, "Un testimonio temprano de timbre ciceante de la $z$ española", $C L R(14), 179-186$.

${ }^{23}$ M. SÁNCHEZ, "En torno a [d] y [đ]] del español medieval", CLR (16).

${ }^{24} \mathrm{~J}$. PENELla, op. cit., p. 450 , nota 3.

${ }^{25}$ J. PEREGo, "Les sabirs", Le langage, Paris, 1968, p. 604.

${ }^{26}$ A. GALMÉs DE FUENTES, "Sobre un soneto barroco de un morisco", $A O$, $27 / 28(1977-78)$. 
presentar ciertas similitudes, ya que se nutre de la lengua común, está adscrita a un sector determinado - y marginado - de la sociedad, etc., no cumple el objetivo de ser una lengua críptica, esencial en los $\operatorname{argots}^{27}$. Si bien las obras podrían haber resultado difíciles de entender a los cristianos por su apariencia arabizante, eran de por sí obras clandestinas que, por su carácter islámico, no trascendían al resto de la sociedad, y era innecesaria así la adopción de una forma críptica en la expresión.

En realidad, el ejemplo más próximo tanto por los resultados que produjo como por los factores socioculturales que lo condicionaron, lo hallamos en el ladino, con el que presenta muchos paralelismos funcionales y formales y, pensamos, puede aportar una base importante de comparación para el estudio de la aljamía morisca, aunque posteriormente en otros momentos de la historia, las consecuencias lingüísticas entre ambas aljamías hayan sido diferentes.

Los judíos españoles utilizaron también para la transliteración de sus textos sagrados al castellano, otro alfabeto, el hebreo, que correspondía a la lengua en la que se había revelado y regulado su religión: fijaron en castellano una lengua semisagrada que al calcar fielmente la estructura de la hebrea garantizaba la veracidad y eficacia de su contenido, caracterizada también por el literalismo de las traducciones, el arcaísmo lingüístico y el hebraísmo léxico, semántico y sintáctico ${ }^{28}$. Sobre la base del castellano y de sus variedades hicieron una "especie de koiné" ${ }^{29}$, que se denominó ladino, sin que esta lengua representara el reflejo de la lengua oral de los judíos, que no era otra que la de los cristianos de las respectivas zonas que habitaron, y de la que en ocasiones se produjo alguna infiltración.

Esa lengua-calco no fue la única manifestación de este tipo, pues se produjo también, y obedece a muy parecidos condicionamientos, en otros países en los que los judíos se establecieron, combinándose con las lenguas vernáculas correspondientes ${ }^{30}$. Del mismo modo que entre los musulmanes que profesaron su religión fuera de los países de lengua árabe, establecieron, también con fines litúrgicos, una lengua que sobre la base de las lenguas verná-

${ }^{27}$ D. FrançoIS, "Les argots", Le langage, Paris, 1968, p. 623.

${ }^{28}$ H. VIDAL SEPHIHA, Le ladino, judéo-espagnol calque, Paris, 1973.

${ }^{29}$ E. Alargos Llorach, "La lengua de los Proverbios morales de Don Sem Tob", RFE, 25 (1951), 249-309.

30 H. VID,L.StPIHH, op.cit., p. 42 , nota 28. 
culas adoptadas calcó la estructura de la árabe, cuyo proceso es paralelo al de la aljamía que escribieron y leyeron en España.

Sin embargo, este gran paralelismo que pensamos existe entre la aljamía de los moriscos y el ladino de los judíos en territorio español, se ve truncado en el devenir histórico posterior a la expulsión de las dos comunidades. Fuera ya del territorio español en el que se habían producido, los judíos mantuvieron en muchos casos el español (que habría de irse deteniendo en su evolución) como lengua conversacional y el ladino para las funciones litúrgicas mencionadas. Los moriscos, que en principio conservaron el habla de sus lugares de origen, lo que suponía una desventaja en su nueva integración, acabaron por abandonar el español, y la aljamía, que en un medio arabófono no tenía ya ninguna razón de existir.

En conclusión, creemos pues, que fueron básicamente factores extralingüísticos, derivados de la profesión de una distinta fe, los que condicionaron originariamente la aparición de estas aljamías, y fomentaron su desarrollo paralelo en territorio español. También fueron factores socioculturales que dependían en parte de la práctica de una religión y en parte de un diverso modo de integración, los que determinaron - o no - su conservación, así como la lengua vernácula española que las sustentaba. Mientras que la mayor parte de la población morisca fue acogida por países de religión musulmana, y se asimilaron progresivamente $^{31}$, en los países donde se establecieron los judíos siguieron persistiendo las diferencias de religión ${ }^{32}$.

MERCEDES SÁNCHEZ ÁLVAREZ

Universidad de Oviedo.

${ }^{31}$ M. EPALzA, "Trabajos actuales sobre la comunidad de moriscos refugiados en Túnez, desde el siglo XVII a nuestros días", Actas, pp. 427-444.

${ }^{32}$ La importancia de este factor ha sido señalada por Weinreich, cuyas palabras citamos textualmente: "Une différence de religion, parallèle a la difference de langue maternelle, peut avoir de répercussions idiomatiques indirectes fort importantes" (Le langage, "Unilinguisme et multilinguisme", Paris, 1968, p. 681). 